\title{
MOTIVASI PETANI DALAM BUDIDAYA LEBAH MADU (Apis Cerana) DI DESA BUANA SAKTI KABUPATEN LAMPUNG TIMUR
}

\author{
(FARMER MOTIVATION OF HONEY BEE (Apis Cerana) \\ IN BUANA SAKTI VILLAGE, LAMPUNG EAST)
}

\author{
Hendra Marti Sya'ban, Christine Wulandari, dan Rudi Hilmanto \\ Jurusan Kehutanan, Fakultas Pertanian, Universitas Lampung \\ Jl. Prof. Dr. Sumantri Brojonegoro No. 1 Bandar Lampung \\ Email: hendramartisyaban@yahoo.com Phone: 08976116394
}

\begin{abstract}
ABSTRAK
Salah satu upaya dalam meningkatkan produksi lebah madu (Apis cerana) adalah melalui pemberian motivasi kepada petani dan keluarganya karena hal tersebut dapat dilakukan dengan peningkatan pendapatan yang ditempuh melalui budidaya lebah madu (Apis cerana) di Desa Buana Sakti. Penelitian yang dilakukan pada bulan Januari sampai Maret 2013 bertujuan untuk mengetahui tingkat motivasi petani dan faktor-faktor yang berhubungan dan berpengaruh terhadap motivasi petani dalam budidaya lebah madu (Apis cerana). Berdasarkan hasil simulasi model SPSS beberapa uji motivasi petani dalam budidaya lebah madu (Apis cerana) di Desa Buana Sakti sudah tergolong tinggi dengan nilai 18,78 dan faktor-faktor yang berpengaruh terhadap motivasi petani dalam budidaya lebah madu (Apis cerana) adalah kemudahan dalam berbudidaya lebah madu 90,7\%, kemudahan dalam pemasaran hasil budidaya lebah madu $90 \%$, frekuensi mengikuti penyuluhan $89,9 \%$, pendapatan petani $85,9 \%$, dan lama berusahatani lebah madu $78,8 \%$.
\end{abstract}

Kata kunci: budidaya, lebah madu (Apis cerana), motivasi, SPSS

\section{ABSTRACT}

One of the efforts to increase the production of honey bee (Apis cerana) is by giving motivate to farmer and their family, because it can be done by increasing the income can be taken by honey bee cultivation (Apis cerana) in Buana Sakti village. This research was done from January until March 2013 to know at the level of farmers' motivation and also the factors that has correlation and influence with the farmers' motivation in honey bee (Apis cerana) cultivation. Based on the result of some model simulations in test the motivation of the farmers in honey bee (Apis cerana) cultivation in Buana Sakti village has been become high classification with result 18,78, and factors that has influence of motivation to farmers in honey bee Apis cerana cultivation is an easy in honey bee cultivation 90,7\%, an easy of market result honey bee cultivation 90\%, frequency to follow socialitation 89,9\%, farmer's income $85,9 \%$, and a long of honey bee cultivation $78,8 \%$.

Key word : cultivation, honey bee (Apis cerana), motivation, SPSS 


\section{PENDAHULUAN}

Hasil Hutan Bukan Kayu (HHBK) merupakan hasil hutan baik nabati maupun hayati beserta produk turunannya dan budidayanya kecuali kayu yang sudah ditetapkan Peraturan Menteri Kehutanan Nomor 35/MENHUT-II/2007 tentang Hasil Hutan Bukan Kayu. Salah satu Hasil Hutan Bukan Kayu (HHBK) yang memiliki potensi besar terpendam di hutan dan belum digali untuk dikelola secara lestari sampai saat ini adalah lebah madu (Asmanah, \& Kuntadi, 2012). Salah satu desa yang sudah dijumpai dengan pengelolaan budidaya lebah madu sebagai HHBK merupakan salah satu pusat pengembangan serta produksi lebah madu Apis cerana di Desa Buana Sakti Kecamatan Batanghari Kabupaten Lampung Timur di provinsi Lampung (Badan Pusat Statistik Kabupaten Lampung Timur, 2012). Salah satu upaya dalam meningkatkan produksi lebah madu Apis cerana adalah melalui pemberian motivasi atau dorongan-dorongan kepada petani dan keluarganya (Winda, 2012). Motivasi merupakan dorongan yang timbul dari dalam diri seseorang yang didasarkan atas kebutuhan sehingga suatu kegiatan yang dilaksanakan mencapai suatu tujuan tertentu (Wahjosumidjo, 1987).

Tujuan utama petani melakukan budidaya lebah madu adalah untuk memenuhi kebutuhan individu petani dan anggota keluarga yang menjadi tanggungannya, hal tersebut dapat dilakukan dengan peningkatan pendapatan yang ditempuh melalui budidaya lebah madu (Adalina, 2011). Apriyanita (2012) mengemukakan bahwa penduduk Buana Sakti menjadikan hasil perkebunan dan pertanian sebagai sumber pendapatan utama. Usaha budidaya lebah di Desa Buana Sakti merupakan usaha sampingan, namun jika petani lebah mengelolanya dengan tepat guna dan mulai memproduksi lebah seperti madu, lilin lebah, propolis, dan lainnya maka petani lebah akan memperoleh keuntungan. Wahjosumidjo (1987) mengemukakan bahwa faktor-faktor yang mendorong petani untuk membudidayakan lebah madu Apis cerana terdiri dari dua faktor, yaitu faktor internal dan eksternal. Faktor yang berasal dari luar diri petani disebut juga faktor eksternal seperti pengaruh lingkungan atau dorongan dari penyuluh. Faktor internal yaitu faktor yang berasal dari dalam diri petani, seperti tingkat pendidikan dan pengalaman. Kedua faktor tersebut mempengaruhi tingkat motivasi petani dalam budidaya lebah madu.

Penelitian ini bertujuan untuk mengetahui tingkat motivasi petani dalam budidaya lebah madu Apis cerana serta mengetahui faktor-faktor yang berhubungan dan berpengaruh terhadap motivasi petani dalam budidaya lebah madu Apis cerana di Desa Buana.

\section{METODE PENELITIAN}

Penelitian ini dilakukan di Desa Buana Sakti Kecamatan Batanghari Kabupaten Lampung Timur dilakukan dari bulan Januari sampai Maret 2013 karena pada bulan tersebut, lebah madu mendapat banyak perhatian untuk dilestarikan dengan upaya penangkaran sehingga meningkatkan pendapatan petani lebah madu, hal ini didukung dengan pernyataan dari Smith dan Ferguson (2009) yaitu Apis cerana memiliki daya adaptasi yang tinggi pada bulan Desember sampai Juni dengan temperatur rata-rata $24-34^{0} \mathrm{C}$.

Penelitian ini terdiri dari 2 data, yaitu data primer dan sekunder. Data primer diperoleh melalui wawancara secara langsung dengan menggunakan daftar pertanyaan (kuisioner yang telah disusun), sedangkan data sekunder diperoleh dari Dinas atau Instansi terkait dan Lembaga desa serta literatur yang berhubungan dengan penelitian ini. Responden pada penelitian ini adalah kelompok tani di Desa Buana Sakti Kecamatan Batanghari Kabupaten Lampung Timur bernama "Karya Tani Sejahtera" yang terdiri dari 23 anggota (Purwadi, Pengurus Kelompok Tani). Pemilihan responden ini berdasarkan keterangan dari Badan Pusat 
Statistik (BPS) Kabupaten Lampung Timur (2012) yaitu Desa Buana Sakti merupakan salah satu sentra pengembangan dan produksi lebah madu di Provinsi Lampung. Selain itu, kelompok tani lebah madu yang terdapat di daerah tersebut hanya kelompok Karya Tani Sejahtera.

Analisis data yang akan digunakan dalam penelitian ini bersifat kuantitatif dan deskriptif. Sugiyono (2009) mengemukakan, kuantitatif merupakan penelitian menggunakan data berupa angka-angka dan bersifat sistematis. Karena pada penelitian ini data input dan output yang dihasilkan oleh software SPSS (Statistical Product and Service Solution.) berupa angka dan dalam perhitungan atau penyelesaian nilai tingkat motivasi (Variabel Y) ini dilakukan secara sistematis yaitu dengan persamaan regresi linier berganda. Selanjunya data output dari software SPSS yang diperoleh akan dianalisis secara deskriptif. Pengukuran tingkat motivasi dalam penelitian ini dilakukan dengan menggunakan kuisioner secara sistematis dengan persamaan matematika atau permodelan SPSS versi 16.0. Setiap jawaban dari pertanyaan kuisioner masing-masing jawaban disesuaikan dengan Skala yang sering dipakai dalam Skala Likert, yaitu skala yang berisi lima tingkat preferensi jawaban dengan pilihan sebagai berikut: 1 = sangat tidak setuju; 2 = tidak setuju; $3=$ ragu-ragu atau netral; $4=$ setuju; 5 = sangat setuju. Selanjutnya, penentuan kategori interval tinggi, sedang, atau rendah tingkat motivasi dalam budidaya lebah madu digunakan rumus sebagai berikut :

$I=\frac{N T-N R}{K}$

Keterangan :

$\mathrm{I} \quad=$ Interval;

NT $=$ Total nilai tertinggi;

$\mathrm{NR}=$ Total nilai terendah;

$\mathrm{K}=$ Kategori jawaban (Yitnosumarto, 2006).

Penggunaan rumus tersebut berdasarkan dari pengelompokkan nilai Skala Likert dalam kuisioner di tiap jawabannya. Yitnosumarto (2006) menjelaskan bahwa hasil dari nilai interval tersebut diklasifikasikan kembali ke dalam kategori interval berikut:

1. Tingkat usaha budidaya sangat tinggi $=$ Skor 21,5-25;

2. Tingkat usaha budidaya tinggii = Skor $17,9-21,4$;

3. Tingkat usaha budidaya sedang = Skor $13,9-17,8$;

4. Tingkat usaha budidaya rendah $=$ Skor $10,3-13,8$;

5. Tingkat usaha budidaya sangat rendah $=$ Skor $6,7-10,2$.

Pengklasifikasian tersebut merupakan penentuan tingkat motivasi petani dalam budidaya lebah madu. Pengolahan dan analisis data dilakukan dengan metode tabulasi dan gambar. Tabulasi berarti jawaban dikelompokkan kemudian dimasukkan kedalam tabel dengan cara yang teliti dan teratur berdasarkan kategori jawaban pertanyaan. Pada tabulasi masing-masing responden diberi kode berdasarkan urutan angka. Data yamg diperoleh baru dapat berguna bila alat ukur yang digunakan baik yaitu bilamana alat ukur memiliki ciri sebagai alat ukur yang baik, ciri-ciri alat ukur yang baik antara lain; 1.memiliki validitas yang cukup tinggi; 2.memiliki realibiltas yang baik; 3.memiliki nilai kepraktisan. Skor masingmasing variabel hasil kuisioner yang didapat kemudian dianalisis dalam permodelan SPSS secara sistematis. 
HASIL DAN PEMBAHASAN

\section{Deskripsi variabel-variabel yang berhubungan dan berpengaruh terhadap motivasi petani dalam budidaya lebah madu Apis cerana}

Penelitian tentang motivasi petani dalam budidaya budidaya lebah madu di Desa Buana Sakti terdiri dari lama usaha tani $\left(\mathrm{X}_{1}\right)$, tingkat pendapatan petani $\left(\mathrm{X}_{2}\right)$, frekuensi mengikuti penyuluhan $\left(\mathrm{X}_{3}\right)$, kemudahan dalam berusahatani lebah madu Apis cerana $\left(\mathrm{X}_{4}\right)$, kemudahan dalam pemasaran hasil budidaya lebah madu Apis cerana $\left(\mathrm{X}_{5}\right)$.

Faktor-faktor yang diambil adalah faktor yang dominan atau ada kesamaan dari kedua penelitian yang mempengaruhi motivasi dalam budidaya lebah madu di Desa Buana Sakti.

Tabel 1. Rekapitulasi data variabel-variabel motivasi petani dalam usaha budidaya lebah madu Apis cerana

\begin{tabular}{lcc}
\hline $\begin{array}{l}\text { Faktor-faktor yang berhubungan dengan motivasi petani } \\
\text { dalam budidaya lebah madu Apis cerana }\end{array}$ & Modus & Klasifikasi \\
\hline 1. Lama dalam berusahatani budidaya & 19,88 & Tinggi \\
2. Pendapatan petani dalam budidaya & 19,56 & Tinggi \\
3. Frekuensi petani mengikuti penyuluhan & 17,6 & Sedang \\
4. Kemudahan petani dalam berusahatani & 16,64 & Sedang \\
5. Kemudahan dalam pemasaran hasil budidaya & 20,2 & Tinggi \\
\hline Modus : Motivasi petani dalam usaha & & \\
\multicolumn{1}{l}{ budidaya lebah madu Apis cerana } & 18,78 & Tinggi \\
\hline
\end{tabular}

Hasil penelitian menunjukkan bahwa dengan nilai 18,78 pada tabel 1., termasuk dalam klasifikasi tinggi. Hal ini berarti bahwa petani responden di Desa Buana Sakti mempunyai motivasi yang tinggi dalam budidaya lebah madu Apis cerana. Adanya tingkat motivasi petani lebah madu dalam berusahatani di Desa Buana Sakti dengan menguji variebel-variebel yang berhubungan dengan motivasi petani. Pengukuran tingkat motivasi dalam penelitian ini menggunakan kuisinoer berisikan 25 item pertanyaan secara sistematis dengan persamaan matematika atau pemodelan SPSS versi 16.0.

\section{Hasil Uji Validitas}

Pengujian masing-masing indikator valid atau tidaknya, dapat dilihat dalam tampilan output Cronbach Alpha pada kolom Correlated Item-Total Correlation yang ada di software SPSS. Apabila $\mathrm{r}$ hitung lebih besar dari $\mathrm{r}$ tabel dan nilai positif maka butir atau pertanyaan atau indikator tersebut dinyatakan valid (Arikunto, 2008).

Berdasarkan perhitungan dengan menggunakan program SPSS 16.0, diperoleh data hasil uji validitas pada tabel 2, diketahui bahwa dari 25 item kuisioner tingkat motivasi petani dalam budidaya lebah madu Apis cerana menyatakan semua item kuisioner VALID dengan nilai $r$ tabel koefisien korelasi dengan taraf signifikan $5 \%(0,05)$ atau $r$ hitung $>0,404$ pada $r$ tabel (Soenyono, 2007). Setelah semua item valid, baru semua item yang valid tersebut kemudian diukur reliabilitasnya. 
Tabel 2. Hasil Uji Vialiditas.

\begin{tabular}{ccccc}
\hline & $\begin{array}{c}\text { Scale Mean if Item } \\
\text { Deleted }\end{array}$ & $\begin{array}{c}\text { Scale Variance if Item } \\
\text { Deleted }\end{array}$ & $\begin{array}{c}\text { Corrected Item-Total } \\
\text { Correlation }\end{array}$ & $\begin{array}{c}\text { Cronbach's Alpha if } \\
\text { Item Deleted }\end{array}$ \\
\hline TIPE1.1 & 97.7826 & 80.723 & .433 & .939 \\
TIPE1.2 & 97.5652 & 78.802 & .569 & .937 \\
TIPE1.3 & 98.0870 & 78.356 & .518 & .938 \\
TIPE1.4 & 97.5217 & 77.352 & .731 & .935 \\
TIPE1.5 & 97.4783 & 77.352 & .731 & .935 \\
TIPE2.1 & 97.8696 & 80.482 & .580 & .937 \\
TIPE2.2 & 97.8261 & 76.514 & .519 & .939 \\
TIPE2.3 & 97.6957 & 79.130 & .577 & .937 \\
TIPE2.4 & 97.3913 & 78.704 & .591 & .937 \\
TIPE2.5 & 97.9565 & 75.680 & .729 & .935 \\
TIPE3.1 & 99.3478 & 74.692 & .728 & .935 \\
TIPE3.2 & 97.3913 & 78.158 & .654 & .936 \\
TIPE3.3 & 97.5217 & 77.715 & .689 & .936 \\
TIPE3.4 & 99.1739 & 74.150 & .535 & .940 \\
TIPE3.5 & 97.4348 & 76.621 & .614 & .936 \\
TIPE4.1 & 99.6087 & 78.613 & .601 & .937 \\
TIPE4.2 & 98.3043 & 79.040 & .588 & .937 \\
TIPE4.3 & 98.4348 & 77.348 & .738 & .935 \\
TIPE4.4 & 97.7826 & 76.996 & .760 & .935 \\
TIPE4.5 & 97.7826 & 76.632 & .685 & .935 \\
TIPE5.1 & 97.4783 & 78.534 & .595 & .937 \\
TIPE5.2 & 97.4348 & 78.621 & .590 & .937 \\
TIPE5.3 & 97.6087 & 78.704 & .591 & .937 \\
TIPE5.4 & 97.7391 & 79.020 & .621 & .937 \\
TIPE5.5 & 97.7826 & 76.542 & .504 & .939 \\
\hline
\end{tabular}

Tabel 3. Hasil Uji Reliabilitas.

\begin{tabular}{|c|c|c|c|}
\hline \multirow[t]{5}{*}{ Cronbach's Alpha } & Part 1 & Value & .899 \\
\hline & & $\mathrm{N}$ of Items & $13^{\mathrm{a}}$ \\
\hline & Part 2 & Value & .880 \\
\hline & & $\mathrm{N}$ of Items & $12^{\mathrm{b}}$ \\
\hline & Total $\mathrm{N}$ of Items & & 25 \\
\hline \multicolumn{3}{|c|}{ Correlation Between Forms } & .842 \\
\hline \multirow{2}{*}{$\begin{array}{l}\text { Spearman-Brown } \\
\text { Coefficient }\end{array}$} & Equal Length & & .914 \\
\hline & Unequal Length & & .914 \\
\hline \multicolumn{2}{|c|}{ Guttman Split-Half Coefficient } & & .914 \\
\hline
\end{tabular}

Berdasarkan perhitungan dengan menggunakan program SPSS 16.0, diperoleh data hasil uji reliabilitas pada tabel 3. Hasil analisis reliabilitas diperoleh nilai koefisien reliabilitas Split-Half (dengan metode Guttman) yaitu sebesar 0,914. Nilai koefisien reliabilitas ini dikontrol dengan nilai $\mathrm{r}$ tabel dengan $\mathrm{df}=\mathrm{n}-2$ baik pada taraf signifikan $1 \%$ maupun $5 \%$. Dengan kriteria uji jika nilai koefisien reliabilitas $>\mathrm{r}$ tabel maka data tersebut reliabel (Soenyono, 2007). Karena nilai koefisien reliabilitas $(0,914)>r$ tabel dengan taraf nyata $(5 \%)$ $(0,404)$ maupun $\mathrm{r}$ tabel dengan taraf nyata ${ }_{(1 \%)}(0,515)$ maka nilai koefisien reliabilitas 
tersebut signifikan atau dengan kata lain data yang dibuat sudah RELIABEL. Setelah mendapatkan data yang diuji valid dan konsisten (reliabilitas), maka data harus mengikuti distribusi normal merupakan syarat dari teknik statistik parametrik.

\section{Hasil Uji Normalitas}

Berdasarkan perhitungan dengan menggunakan program SPSS 16.0, diperoleh data hasil uji normalitas pada tabel 4 .

Tabel 4. Hasil uji Normalitas.

\begin{tabular}{lrrrrrrr}
\hline $\begin{array}{l}\text { One-Sample Kolmogorov- } \\
\text { Smirnov Test }\end{array}$ & TIPE1 & TIPE2 & TIPE3 & TIPE4 & TIPE5 \\
\hline $\mathrm{N}$ & & 23 & 23 & 23 & 23 & 23 \\
Normal Parameters & aean & 21.6087 & 21.2609 & 19.1304 & 18.0870 & 21.9565 \\
& Std. & 1.94794 & 2.00493 & 2.56381 & 1.97514 & 1.87030 \\
Most Extreme & Deviation & Absolute & .187 & .247 & .158 & .156 & .174 \\
Differences & Positive & .187 & .247 & .145 & .144 & .174 \\
& Negative & -.154 & -.131 & -.158 & -.156 & -.146 \\
Kolmogorov-Smirnov Z & .896 & 1.187 & .760 & .750 & .833 \\
Asymp. Sig. (2-tailed) & .398 & .120 & .611 & .628 & .491 \\
\hline
\end{tabular}

Hasil uji yang dilakukan menggunkan uji normalitas dengan menggunakan metode 1Sample Kolmogorov Smirnov karena dalam penelitian tes tidak menetapkan syarat-syarat tertentu mengenai parameter-parameter populasi yang menjadi sampel. Umumnya jenis uji normalitas dengan metode ini dilakukan pada saat uji statistik parametrik dan uji grafik tidak terpenuhi (Soenyono, 2007). Data pada tabel One-Sample Kolmogorov Smirnov Test nilai Asymp. Sig (2-tiled) untuk variabel lama usaha budidaya (tipe1/ $\mathrm{X}_{1}$ ) sebesar 0,398, pendapatan petani (tipe $2 / \mathrm{X}_{2}$ ) sebesar 0,120 , frekuensi mengikuti penyuluhan (tipe3/X $\mathrm{X}_{3}$ ) sebesar 0,611 , kemudahan usaha dalam budidaya (tipe $4 / \mathrm{X}_{4}$ ) sebesar 0,628 dan kemudahan dalam pemasaran hasil budidaya lebah madu Apis cerana (tipe5/ $\mathrm{X}_{5}$ ) sebesar 0,491. Karena semua variabel mempunyai nilai probabilitas lebih besar dari $\alpha(0,025)$ sehingga dapat disimpilkan bahwa semua variabel (tipe1, tipe2, tipe3, tipe4, dan tipe5) terdistribusi secara NORMAL.

\section{Hasil Uji Korelasi}

Berdasarkan perhitungan dengan menggunakan program SPSS 16.0, diperoleh data hasil analisis korelasi Product Moment (Pearson) pada tabel 5. 
Tabel 5. Hasil uji korelasi.

\begin{tabular}{|c|c|c|c|c|c|c|c|}
\hline & & TIPE1 & TIPE2 & TIPE3 & TIPE4 & TIPE5 & RERATA \\
\hline \multirow[t]{3}{*}{ TIPE1 } & Pearson Correlation & 1 & $.598^{\pi *}$ & $.657^{* *}$ & $.754^{* *}$ & $.606^{* \pi}$ & $.788^{\mathrm{x}}$ \\
\hline & Sig. (2-tailed) & & .003 & .001 & .000 & .002 & .000 \\
\hline & $N$ & 23 & 23 & 23 & 23 & 23 & 23 \\
\hline \multirow[t]{3}{*}{ TIPE2 } & Pearson Correlation & $.598^{* *}$ & 1 & $.692^{* *}$ & $.763^{* *}$ & $.791^{* *}$ & $.859^{* *}$ \\
\hline & Sig. (2-tailed) & .003 & & .000 & .000 & .000 & .000 \\
\hline & $N$ & 23 & 23 & 23 & 23 & 23 & 23 \\
\hline \multirow[t]{3}{*}{ TIPE3 } & Pearson Correlation & $.657^{* *}$ & $.692^{* *}$ & 1 & $.761^{* *}$ & $.769^{x \times}$ & $.899^{* x}$ \\
\hline & Sig. (2-tailed) & .001 & .000 & & .000 & .000 & .000 \\
\hline & $\mathrm{N}$ & 23 & 23 & 23 & 23 & 23 & 23 \\
\hline \multirow[t]{3}{*}{ TIPE4 } & Pearson Correlation & $.754^{* *}$ & $.763^{* *}$ & $.761^{* *}$ & 1 & $.838^{* *}$ & $.907^{* *}$ \\
\hline & Sig. (2-tailed) & .000 & .000 & .000 & & .000 & .000 \\
\hline & $\mathrm{N}$ & 23 & 23 & 23 & 23 & 23 & 23 \\
\hline \multirow[t]{3}{*}{ TIPE5 } & Pearson Correlation & $.606^{* *}$ & $.791^{* *}$ & $.769^{* *}$ & $.838^{\pi *}$ & 1 & $.900^{* x}$ \\
\hline & Sig. (2-tailed) & .002 & .000 & .000 & .000 & & .000 \\
\hline & $N$ & 23 & 23 & 23 & 23 & 23 & 23 \\
\hline \multirow[t]{3}{*}{ RERATA } & Pearson Correlation & $.788^{* *}$ & $.859^{* *}$ & $.899^{* *}$ & $.907^{* *}$ & $.900^{* *}$ & 1 \\
\hline & Sig. (2-tailed) & .000 & .000 & .000 & .000 & .000 & \\
\hline & $\mathrm{N}$ & 23 & 23 & 23 & 23 & 23 & 23 \\
\hline
\end{tabular}

Ada 2 hal yang perlu diperhatikan yaitu nilai Pearson Correlations dan Sig. Soenyono (2007) menyatakan bahwa nilai korelasi/hubungan yang tinggi yaitu yang mempunyai nilai korelasi mendekati satu. Berdasarkan data pada tabel 5 diperoleh nilai :

1. Korelasi antara lama usaha budidaya dengan motivasi petani yaitu sebesar 0,788 dengan nilai signifikasi 0,000 yang menunjukkan derajat hubungan yang tinggi.

2. Korelasi antara pendapatan petani dengan motivasi petani yaitu sebesar 0,859 dengan nilai signifikasi 0,000 yang menunjukkan derajat hubungan yang tinggi.

3. Korelasi antara frekuensi petani mengikuti penyuluhan dengan motivasi petani yaitu sebesar 0,899 dengan nilai signifikasi 0,000 yang menunjukkan derajat hubungan yang tinggi.

4. Korelasi antara kemudahan usaha dalam budidaya dengan motivasi petani yaitu sebesar 0,907 dengan nilai signifikasi 0,000 yang menunjukkan derajat hubungan yang tinggi.

5. Korelasi antara kemudahan dalam pemasaran hasil budidaya lebah madu Apis cerana dengan motivasi petani yaitu sebesar 0,900 dengan nilai signifikasi 0,000 yang menunjukkan derajat hubungan yang tinggi.

\section{Hasil Analisis Regresi Linier Berganda, Uji F dan Uji t}

Analisis regresi linier berganda dilakukan pada lebih dari satu variabel independen (bebas). Pada analisis regresi linier berganda ini dapat dilihat pengaruh beberapa variabel independen $(\mathrm{X})$ terhadap variabel dependen (Y). Hasil analisis hubungan antara variabel bebas (X) yaitu lama berusahatani, pendapatan rumah tangga, frekuensi mengikuti penyuluhan, kemudahan dalam berusahatani, dan kemudahan dalam pemasaran hasil dengan variabel terikat (Y) yaitu motivasi petani dalam budidaya lebah madu Apis cerana, yang diukur menggunakan persamaan regresi pada software SPSS disajikan pada tabel 6 dan tabel 7. 
Tabel 6. Hasil Regresi Linier Berganda.

\begin{tabular}{rrrr}
\hline $\mathrm{R}$ & $\mathrm{R}$ Square & Adjusted R Square & Std. Error of the Estimate \\
\hline $.990^{\mathrm{a}}$ & .979 & .973 & .31219 \\
\hline
\end{tabular}

a. Predictors: (Constant), TIPE5, TIPE1, TIPE2, TIPE3, TIPE4

Tabel 7. Hasil Uji F.

\begin{tabular}{llrrrrr}
\hline Model & & Sum of Squares & df & Mean Square & F & Sig. \\
\hline 1 & Regression & 78.082 & 5 & 15.616 & 160.232 & $.000^{\mathrm{a}}$ \\
& Residual & 1.657 & 17 & .097 & & \\
& Total & 79.739 & 22 & & &
\end{tabular}

a. Predictors: (Constant), TIPE5, TIPE1, TIPE2, TIPE3, TIPE4

b. Dependent Variable: MOTIVASI

Tabel 8. Uji t.

\begin{tabular}{|c|c|c|c|c|c|c|}
\hline & \multirow[t]{2}{*}{ Model } & \multicolumn{2}{|c|}{$\begin{array}{l}\text { Unstandardized } \\
\text { Coefficients }\end{array}$} & \multirow{2}{*}{$\frac{\begin{array}{c}\text { Standardized } \\
\text { Coefficients }\end{array}}{\text { Beta }}$} & \multirow[b]{2}{*}{$\mathrm{t}$} & \multirow[b]{2}{*}{ Sig. } \\
\hline & & $\mathrm{B}$ & Std. Error & & & \\
\hline \multirow[t]{6}{*}{1} & (Constant) & -.330 & .963 & & -.343 & .736 \\
\hline & TIPE1 & .175 & .054 & .179 & 3.254 & .005 \\
\hline & TIPE2 & .208 & .057 & .219 & 3.621 & .002 \\
\hline & TIPE3 & .247 & .045 & .333 & 5.538 & .000 \\
\hline & TIPE4 & .158 & .077 & .163 & 2.042 & .057 \\
\hline & TIPE5 & .229 & .077 & .225 & 2.984 & .008 \\
\hline
\end{tabular}

Hasil pada tabel menampilkan data berupa, besarnya nilai korelasi antara variabel bebas (X) dengan variabel terikat (Y) yaitu motivasi petani sebesar 0,990 (kolom R) dan Besarnya nilai koefisien determinasi (daya dukung) variabel bebas $(\mathrm{X})$ dalam memprediksi/menentukan besarnya variabel terikat (Y) yaitu motivai petani sebesar 0,979 atau 97,9\% (kolom R Square). Pengaruh secara bersama antara variabel lama berusahatani, pendapatan petani, frekuensi mengikuti penyuluhan, kemudahan dalam berusahatani, dan kemudahan dalam pemasaran hasil budidaya lebah madu (Apis cerana) terhadap motivasi petani, dapat dilihat pada tabel 9.

Tabel 9. Hasil perhitungan Analisis Regresi Linier Berganda

\begin{tabular}{ccccccc}
\hline $\begin{array}{c}\text { Variabel } \\
\text { terikat }\end{array}$ & $\begin{array}{c}\text { Variabel } \\
\text { bebas }\end{array}$ & $\mathrm{B}$ & $\mathrm{SE}$ & $\mathrm{Beta}$ & $\mathrm{t}$ & Sig \\
\hline $\mathrm{Y}$ & $\mathrm{X} 1$ & $-0,330$ & 0,963 & & $-0,343$ & 0,736 \\
& $\mathrm{X} 2$ & 0,175 & 0,054 & 0,179 & 3,254 & 0,005 \\
& $\mathrm{X} 3$ & 0,208 & 0,057 & 0,219 & 3,621 & 0,002 \\
& $\mathrm{X} 4$ & 0,158 & 0,077 & 0,163 & 2,042 & 0,057 \\
& $\mathrm{X} 5$ & 0,229 & 0,077 & 0,225 & 2,984 & 0,008 \\
\hline $\mathrm{R}=0,990$ & $\alpha=0.05$ & & & & \\
\hline
\end{tabular}

R Square $=0,979$

Adj.R Square $=0,973$

Standar Error $=0,31219$ 
Hasil analisis regresi pada tabel 9 menunjukkan bahwa koefisien korelasi (R) sebesar 0,990 pada taraf nyata $5 \%$, yang berarti terdapat hubungan yang tinggi antara lama berusahatani $\left(\mathrm{X}_{1}\right)$, pendapatan rumah tangga petani $\left(\mathrm{X}_{2}\right)$, frekuensi mengikuti penyuluhan $\left(\mathrm{X}_{3}\right)$, kemudahan dalam berusahatani $\left(\mathrm{X}_{4}\right)$, dan kemudahan dalam pemasaran hasil dengan motivasi petani dalam budidaya lebah madu Apis cerana $\left(\mathrm{X}_{5}\right)$. Sedangkan nilai koefisien determinasi Adjusted R Square sebesar 0,979 atau sebesar 97,9\% berarti sumbangan variabel lama berusahatani, pendapatan rumah tangga, frekuensi mengikuti penyuluhan, kemudahan dalam berusahatani, dan kemudahan dalam pemasaran hasil terhadap motivasi petani dalam budidaya lebah madu Apis cerana sebesar 97,9\%, sedangkan sisanya 3,1\% dipengaruhi oleh variabel-variabel lain yang tidak terdapat dalam model.

Setelah mengetahui nilai signifikasi pada masing-masing t hitung maka dapat disusun persamaan regresi liner berganda dengan persamaan berikut:

$\mathrm{Y}=\mathrm{a}+\mathrm{b}_{1} \mathrm{X}_{1}+\mathrm{b}_{2} \mathrm{X}_{2}+\mathrm{b}_{3} \mathrm{X}_{3}+\mathrm{b}_{4} \mathrm{X}_{4}+\mathrm{b}_{5} \mathrm{X}_{5}$

$Y=-0,330+0,175 X_{1}+0,208 X_{2}+0,247 X_{3}+0,158 X_{4}+0,229 X_{5}$

Keterangan :

$\mathrm{Y}=$ motivasi petani

$\mathrm{X}_{1}=$ lama usaha petani

$\mathrm{X}_{2}=$ tingkat pendapatan petani

$\mathrm{X}_{3}=$ frekuensi petani mengikuti penyuluhan

$\mathrm{X}_{4}=$ tingkat kemudahan usaha

$\mathrm{X}_{5}=$ tingkat kemudahan dalam pemasaran hasil

$\mathrm{a}=$ nilai intercept (konstan)

$\mathrm{b}=$ angka arah atau koefisien regresi

\section{KESIMPULAN DAN SARAN}

\section{Kesimpulan}

1. Petani yang membudidayakan lebah madu Apis cerana di Desa Buana Sakti Kecamatan Batanghari Kabupaten Lampung Timur memiliki motivasi yang tinggi dalam membudidayakan lebah madu (Apis cerana).

2. Faktor-faktor yang berpengaruh terhadap motivasi petani dalam budidaya lebah madu (Apis cerana) adalah kemudahan dalam berbudidaya lebah madu 90,7\%, kemudahan dalam pemasaran hasil budidaya lebah madu $90 \%$, frekuensi mengikuti penyuluhan 89,9\%, pendapatan petani $85,9 \%$, dan lama berusahatani lebah madu $78,8 \%$.

\section{Saran}

Perlu dilakukan pembinaan tentang budidaya lebah madu Apis cerana secara terusmenerus kepada seluruh kelompok tani Karya tani Sejahtera antara lain pemasaran hasil budidaya lebah madu Apis cerana agar petani mendapat jaringan pasar yang lebih luas . Pembinaan berikutnya adalah diberi bantuan berupa sarana dan prasarana dalam pembudidayaan lebah madu misal, mencukupi jumlah pakan untuk kebutuhan lebah madu yang ada di Desa Buana Sakti.

\section{DAFTAR PUSTAKA}

Asmanah, \& Kuntadi. 2012. Budidaya lebah madu Apis mellifera L. oleh masyarakat pedesaan, Kabupaten Pati, Jawa Tengah. Jurnal Penelitian Hutan dan Konservasi Alam. 9(4):351-361 p. 
Adalina, Y. 2011. Analisis financial usaha lebah madu Apis mellifera L. Jurnal Penelitian Hutan dan Konservasi Alam. 3:217-237 p.

Apriyanita. 2012. Manajemen penangkaran lebah madu (Apis cerana) di Desa Buana Sakti. Skripsi. Universitas Lampung

Arikunto, S. 2008. Prosedur Penelitian Suatu Pendekatan Praktek. Buku. PT Rineka Cipta. Jakarta.

Badan Pusat Statistik Kabupaten Lampung Timur. 2012. Lampung Timur Dalam Angka Tahun 2011. Bandar Lampung.

Departemen Kehutanan. 1999. Peraturan Menteri Kehutanan tentang Hasil Hutan Bukan Kayu. Salinan Kepala Biro Hukum dan Organisasi. Dephutbun. Jakarta.

Pemerintahan Kabupaten Lampung Timur. (Situs Resmi). Geotoporafi Lampung Timur. Diakses tanggal 20 Mei 2012. Pukul 20.00 WIB. Sumber: http://lampungtimurkab.go.id/index.php?mod=menu_2\&opt=sm_10

Smith, \& Ferguson. 2009. Klimatologi Pertanian Indonesia. Buku. Rhineka Cipta. Jakarta Soenyono. 2007. Metode Analisis Data Sosial. Buku. Jenggala Pustaka Utama. Kediri.

Sugiyono. 2009. Metode Penelitian Pendidikan Pendekatan Kuantitatif, Kualitatif dan $R$ \& D. Bandung: Alfabeta.

Tim Karya Tani Mandiri. 2010. Pedoman Budidaya Beternak Lebah Madu. Buku. Nuansa Aulia. Bandung.

Wahjosumidjo. 1987. Kepemimpinan dan Motivasi. Buku. Ghalia Indonesia. Jakarta.

Winda, F. 2012. Prospek pengembangan budidaya lebah madu di Kelurahan Gunung Gede Kecamatan Kawalu Kota Tasikmalaya. Skripsi. Universitas Siliwangi. Tasikmalaya.

Yitnosumarto. 2006. Metode Penelitian Kuantitatif dan Kualitatif. Buku. Yogyakarta. Penerbit Graha Ilmu. 